\title{
Clinical and haematological screening in recurrent aphthae
}

\author{
A. W. HutCHEON* \\ M.D., M.R.C.P. \\ D. WRAY† \\ M.B., B.D.S. \\ J. H. DAGG* \\ M.D., F.R.C.P. \\ M. M. FERGUSON† \\ B.Sc., M.B., F.D.S. \\ D. K. MASON† \\ N. P. LUCIE* \\ M.D., F.D.S., F.R.C.Path., F.R.C.S. \\ B.Sc., M.B., M.R.C.P., M.R.C.Path. \\ *University Department of Medicine, Western Infirmary, Glasgow G11 6NT, and \\ †University Department of Oral Medicine and Pathology, Glasgow Dental Hospital and School, \\ Glasgow G2 3JZ
}

\section{Summary}

A series of 328 consecutive out-patients with recurrent aphthae were screened for deficiencies of iron, folic acid and vitamin $B_{12}$, by examination of the peripheral blood, by assays of serum vitamin $B_{12}$ and corrected whole blood folate, and estimation of the serum iron and total iron binding capacity; deficiencies were demonstrated in 45 patients $(13.7 \%)$. Of these, 31 were deficient in iron, 15 in folic acid and 11 in vitamin $B_{12} ; 11$ patients had combined deficiencies.

Of the 45 aphthae patients with deficiencies, 29 had anaemia or demonstrable abnormalities in the red cell indices or stained blood film, and the assay results were confirmatory. In the remaining 16 patients, no red cell changes were present, and diagnosis depended entirely on reduced levels of serum vitamin $B_{12}$, whole blood folate or iron saturation of transferrin; such latent deficiencies occurred only with iron and folic acid, whereas all patients with vitamin $B_{12}$ deficiency even without anaemia had morphological changes in the blood.

Individual patients with a deficiency could not be distinguished from those without a deficiency on the basis of clinical examination of the mouth ulcers. However, aphthae patients who also had glossitis or angular cheilitis were more likely to suffer from such deficiencies.

Thirty-nine of the deficient aphthae patients available for follow-up were assessed at least 6 months after appropriate replacement therapy; 23 showed a complete remission of ulcers, 11 were improved and 5 were not helped.

It is suggested that the considerable incidence of deficiencies found in this series and the clinical and haematological response to replacement therapy con- firms the need for full screening of patients with rerecurrent aphthae. Since 16 out of 45 of these patients had no anaemia or morphological abnormalities in the peripheral blood, their deficiencies would have been missed on routine haematological examination alone; for this reason it is recommended that screening should also include estimation of the serum iron and total iron-binding capacity, whole blood folate and, possibly vitamin $B_{12}$.

\section{Introduction}

In a previous series of 130 patients with recurrent aphthae (Wray et al., 1975) it was found that deficiences of iron, folic acid and vitamin $B_{12}$ occurred more often than in an age- and sex-matched control group; when such deficiencies were treated there was a significant improvement in their oral ulceration. This original series has been extended and it is the purpose of this paper to evaluate methods, both clinical and laboratory, of screening patients with recurrent aphthae for deficiencies of iron, folic acid and vitamin $B_{12}$.

\section{Patients and methods}

Three hundred and twenty-eight consecutive patients were admitted to the study; the diagnosis of recurrent aphthae fulfilled the criteria of Lehner (1968). The ulcers had been present for periods of 6 months to 40 years (mean 8.6 years). The ages of the patients ranged from 6 to 86 years (mean 35.5 years); 212 were female (mean age 35.1 years) and 116 were male (mean age 33.3 years). Patients with bullae, traumatic ulcers, acute ulcerative gingivitis, herpes simplex and zoster, erythema multiforme, Reiter's syndrome and Behçet's syndrome were 
excluded, as were those whose ulcers were related to the menstrual cycle.

\section{Haematological studies}

Venous blood was taken from all patients at two consecutive clinic visits. The haemoglobin concentration, mean corpuscular volume (MCV) and mean corpuscular haemoglobin (MCH) were measured using a Coulter $\mathbf{S}$ counter and a 5-ml aliquot collected in sequestrene. Stained blood films were examined in all patients, using standard methods (Dacie and Lewis, 1970). Patients were regarded as anaemic if they had a haemoglobin of less than $13.0 \mathrm{~g} / \mathrm{dl}$ in males and less than $12.0 \mathrm{~g} / \mathrm{dl}$ in females. The serum iron and total iron binding capacity were measured by an automated method (Young and Hicks, 1965), and the percentage iron saturation of transferrin calculated; a saturation of less than $16 \%$ was regarded as indicating iron deficiency (Bainton and Finch, 1964). The serum folate and more recently the corrected whole blood folate were measured using a technique modified from that of Waters and Mollin (1961). Folic acid deficiency was diagnosed when the serum folate was less than $2.5 \mu \mathrm{g} / 1$ or the corrected whole blood folate was less than $100 \mu \mathrm{g} / 1$. Serum vitamin $\mathbf{B}_{12}$, assayed using Euglena gracilis (Dacie and Lewis, 1970) was regarded as abnormal below $140 \mathrm{ng} / \mathrm{l}$. Bone marrow examination was carried out in thirty patients.

Patients were regarded as being deficient in iron, folic acid or vitamin $B_{12}$ only if they showed two consecutive results below the normal range.

\section{Clinical studies}

In all patients the duration, type and site of oral ulcers, and the presence of glossitis and angular cheilitis were recorded. Glossitis was diagnosed if the patient complained of discomfort in the tongue or if the mucosa was erythematous or atrophic.

\section{Aetiology of deficiencies}

Patients found to have such deficiencies were investigated further to determine the cause of the deficiency and to initiate treatment.

\section{Treatment}

Patients with iron deficiency were treated with oral iron continuously for a minimum period of 6 months, those with folate deficiency were given oral folic acid $5 \mathrm{mg}$ thrice daily and patients with vitamin $B_{12}$ deficiency were given hydroxocobalamin $1000 \mu \mathrm{g}$ i.m. every 2 months. When more than one deficiency was present, replacement therapy was introduced sequentially to assess the response to each agent separately. Patients shown to have gluten enteropathy were placed on a gluten-free diet, after a trial of specific replacement.
While patients were being investigated they were given symptomatic therapy in the form of a zinc chloride/zinc sulphate mouthwash or a $0.2 \%$ chlorhexidine aqueous mouthwash. In assessing the response to treatment, complete absence of ulcers for at least one year after specific therapy constituted a remission, and the presence of between one and six ulcers per year was a definite improvement. All patients have been followed-up for a minimum of 6 months and up to 9 years (mean 3.5 years).

\section{Results \\ Haematological deficiencies}

Of the 328 patients examined, $45(13.7 \%)$ were found to be deficient in iron, folate or vitamin $B_{12}$. Twenty-one patients $(6.4 \%)$ had iron deficiency only, 7 patients $(2 \cdot 1 \%)$ had pure folate deficiency and 6 patients $(1.8 \%)$ had pure vitamin $\mathrm{B}_{12}$ deficiency. In addition a further 11 patients $(3 \%)$ had combined deficiencies. Of these, 6 were deficient in iron and folic acid, 3 in iron and vitamin $\mathbf{B}_{12}$, one in folic acid and vitamin $B_{12}$, and one patient was deficient in all 3 substances (Table 1 ).

Of the 21 patients with pure iron deficiency, 11 had recognizable changes in the peripheral blood. Five of these patients were overtly anaemic and had abnormal blood films. Six had normal haemoglobin values but

TABLE 1. Incidence of overt and latent deficiencies in 45 patients with recurrent aphthae

\begin{tabular}{lccc}
\hline Deficiency & Number & $\begin{array}{c}\text { Overt } \\
\text { deficiency* }\end{array}$ & $\begin{array}{c}\text { Latent } \\
\text { deficiency }\end{array}$ \\
\hline Iron & 21 & 11 & 10 \\
Folate & 7 & 3 & 4 \\
Vitamin $\mathbf{B}_{12}$ & 6 & 6 & - \\
Iron and folate & 6 & 4 & 2 \\
Iron and vitamin $\mathbf{B}_{\mathbf{1 2}}$ & 3 & 3 & - \\
Folate and vitamin $\mathbf{B}_{12}$ & 1 & 1 & - \\
Iron folate and vitamin $\mathbf{B}_{12}$ & 1 & 1 & - \\
Total & 45 & 29 & 16 \\
\hline
\end{tabular}

* Indicates anaemia \pm any detectable abnormalities in the erythrocytes in the peripheral blood.

$\dagger$ Indicates normal peripheral blood.

reduced $\mathrm{MCV}$ and/or $\mathrm{MCH}$ values, and of these only 2 had abnormal blood films. All had absent stainable iron on marrow examination. The remaining 10 patients had reductions in the serum transferrin saturation only, and thus had latent iron deficiency; marrow examination was performed in 6 patients in this group, and iron deficiency confirmed.

In the 7 patients with pure folic acid deficiency, the peripheral blood was entirely normal in 4 and the diagnosis depended on the assay results alone; 2 of the 4 had bone marrow examination, which 


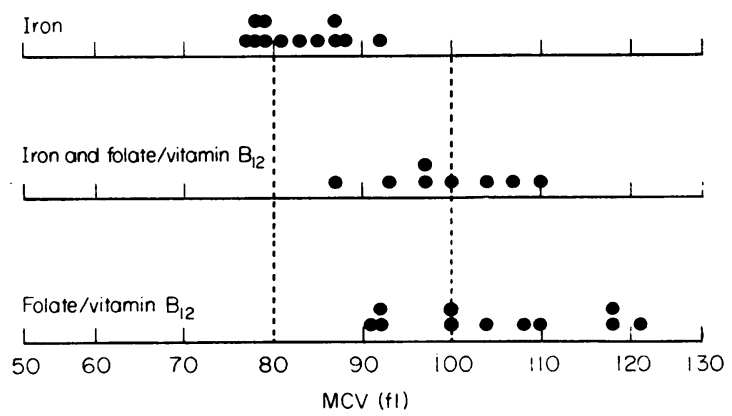

FIG. 1. Distribution of $\mathrm{MCV}$ in patients with pure iron deficiency, iron and folate or vitamin $B_{12}$ deficiency and folate and/or vitamin $B_{12}$ deficiency. (Normal range 80-100 fl.)

showed normoblastic erythropoiesis. The remaining 3 patients were anaemic, had abnormal absolute values, abnormal blood films and megaloblastic erythropoiesis.

All 6 patients with pure vitamin $\mathbf{B}_{12}$ deficiency had changes in the peripheral blood. Three had normal haemoglobin levels; 2 of these had elevated MCV and $\mathrm{MCH}$ values, and an abnormal blood film. The third had an elevated $\mathrm{MCH}$ alone, and in this patient the blood film was normal. All 6 had megaloblastic erythropoiesis.

In the remaining 11 patients, 2 or more deficiencies co-existed. Six patients were deficient in both iron and folic acid; 4 were anaemic but had normal absolute values, and 3 of these patients had normal blood films - the fourth showed macrocytosis. Of these 4 patients only 2 had bone marrow examination performed. One patient with a normal blood film showed normoblastic erythropoiesis and the fourth patient had megaloblastic erythropoiesis. Both had absent stainable iron.

All 3 patients with combined iron and vitamin $B_{12}$ deficiency were anaemic, had elevated absolute values, abnormal blood films and megaloblastic erythropoiesis with absent stainable iron. The remaining 2 patients with combined deficiencies were anaemic with abnormal absolute values, blood films and marrow histology.

Of the 45 patients, therefore, $16(36 \%)$ had no recognizable abnormality in the peripheral blood indices and film. Ten of these patients had latent iron deficiency, 4 pure folic acid deficiency and 2 combined iron and folic acid deficiency (Table 1).

\section{Clinical examination}

The various subgroups of deficiencies were examined to detect any clinical criteria which might be of use in distinguishing deficient patients from patients with recurrent aphthae as a whole. (a) Age and sex. In the deficient group 35 were female and 10 were male (ratio $3.5: 1$ ) and in the non-deficient group the female : male ratio was $1.7: 1(P<0.05)$. The age of the deficient group ranged from 6 to 86 years (mean 40.3 years) and the mean age of the non-deficient group was 34.7 years (n.s.).

(b) Duration of aphthae. The deficient group of patients had aphthae for periods ranging from 6 months to 40 years (mean $7 \cdot 3$ years) and the nondeficient group had a similar range with a mean time of 8.6 years (n.s.).

(c) Type of aphthae. Minor aphthae were seen in $80 \%$ of the deficient patients, major aphthae in $32 \%$, and herpetiform lesions in $14 \%$. Of these patients, $27 \%$ sufferered from major, minor or herpetiform aphthae at different times. The incidence and type of aphthae seen were similar in both the deficient and non-deficient groups and did not differ from the incidence reported elsewhere (Lehner, 1968; Challacombe, Barkham and Lehner, 1977).

(d) Site of aphthae. Buccal and labial mucosal ulceration, which occurred in $85 \%$ of the nondeficient group, was present in all of the deficient group. Ulceration of the soft palate was found in $25 \%$ of the non-deficient group and in $59 \%$ of the deficient group $(P<0.005)$; ulceration of the dorsum of the tongue occurred in $84 \%$ of deficient patients and in only $50 \%$ of the non-deficient group $(P<0.05)$ (Table 2).

Both glossitis and angular cheilitis occurred with an incidence of $21 \%$ in patients with deficiencies while angular cheilitis was seen in only $4 \%$ of patients without such a deficiency $(P<0.0005)$. Glossitis was not seen in the non-deficient group $(P<0 \cdot 0005)$ (Table 3).

TABLE 2. Sites affected by ulcers in patients with recurrent aphthae

\begin{tabular}{lccc}
\hline & $\begin{array}{c}\text { Buccal } \\
\text { and labial } \\
\text { mucosa }\end{array}$ & Soft palate & $\begin{array}{c}\text { Dorsum of } \\
\text { tongue }\end{array}$ \\
\hline $\begin{array}{l}\text { Deficiency group } \\
\begin{array}{l}\text { Non-deficiency } \\
\text { group }\end{array}\end{array}$ & $100 \%$ & $59 \%$ & $84 \%$ \\
$\begin{array}{c}\text { Statistical } \\
\text { significance }\end{array}$ & $85 \%$ & $25 \%$ & $50 \%$ \\
\hline
\end{tabular}

TABLE 3. Incidence of glossitis and angular cheilitis in patients with recurrent aphthae

\begin{tabular}{|c|c|c|}
\hline & Glossitis & $\begin{array}{l}\text { Angular } \\
\text { cheilitis }\end{array}$ \\
\hline $\begin{array}{l}\text { Deficient group } \\
\text { Non-deficient group } \\
\text { Statistical significance }\end{array}$ & $\begin{array}{c}21 \% \\
P<0.0005\end{array}$ & $\begin{array}{c}21 \% \\
\quad 4 \% \\
P<0.0005\end{array}$ \\
\hline
\end{tabular}




\section{Aetiology of deficiencies}

All patients were investigated to define the cause of the deficiency and the results are shown in Table 4. One patient is still under investigation, one died before investigation and one refused investigation. Of the 21 patients with iron deficiency, 10 had menorrhagia. Seven patients had pure folate deficiency and in 5 of these this was due to gluten enteropathy. The 6 patients with pure vitamin $B_{12}$ deficiency all had Addisonian pernicious anaemia.

TABle 4. Associated conditions in patients with deficiencies

\begin{tabular}{|c|c|c|c|}
\hline Deficiency & $\begin{array}{l}\text { No. of } \\
\text { patients }\end{array}$ & Associated condition & \\
\hline Iron & 21 & $\begin{array}{l}\text { Menorrhagia } \\
\text { Dietary } \\
\text { Adenocarcinoma of colon } \\
\text { Diverticular disease of } \\
\text { colon } \\
\text { Idiopathic proctocolitis } \\
\text { Crohn's disease } \\
\text { Under investigation } \\
\text { Refused investigation } \\
\text { Died before investigation }\end{array}$ & $\begin{array}{r}10 \\
4 \\
1 \\
1 \\
1 \\
1 \\
1 \\
1 \\
1\end{array}$ \\
\hline Folic acid & 7 & $\begin{array}{l}\text { Adult coeliac disease* } \\
\text { Dietary } \\
\text { Oral contraceptive }\end{array}$ & $\begin{array}{l}5 \\
1 \\
1\end{array}$ \\
\hline Vitamin $B_{12}$ & 6 & $\begin{array}{l}\text { Addisonian pernicious } \\
\text { anaemia }\end{array}$ & 6 \\
\hline Iron and folic acid & 6 & $\begin{array}{l}\text { Adult coeliac disease } \\
\text { Hiatus hernia and } \\
\text { dietary folate deficiency }\end{array}$ & 5 \\
\hline $\begin{array}{l}\text { Iron and vitamin } \\
\mathrm{B}_{12}\end{array}$ & 3 & $\begin{array}{l}\text { Addisonian pernicious } \\
\text { anaemia } \\
\text { Crohn's disease }\end{array}$ & $\begin{array}{l}2 \\
1\end{array}$ \\
\hline $\begin{array}{l}\text { Folic acid and } \\
\text { vitamin } B_{12}\end{array}$ & 1 & Adult coeliac disease & 1 \\
\hline $\begin{array}{l}\text { Iron, folic acid } \\
\text { and vitamin } B_{12}\end{array}$ & 1 & Adult coeliac disease & 1 \\
\hline
\end{tabular}

* For criteria see Wray et al., 1975.

Six patients had combined folic acid and iron deficiency and 5 of these had gluten enteropathy, the sixth having a hiatus hernia and dietary folic acid deficiency. Three patients had vitamin $B_{12}$ deficiency and co-existent iron deficiency; 2 of these had Addisonian pernicious anaemia and dietary iron deficiency and the third, Crohn's disease. The single patient with deficiencies of folic acid and vitamin $B_{12}$ and the patient with deficiencies of all 3 substances were shown to have adult coeliac disease.

\section{Response to treatment}

All 328 patients were given a mouthwash as local symptomatic treatment. This was only used in the presence of ulcers and hence could not be deemed responsible for lasting clinical improvement. In addition, a maximal remission of only $11 \%$ can be anticipated when purely local treatment is use (Wray et al., 1975).

Response to replacement therapy was assessed as. previously described by Wray et al. (1975). Of the 45 patients with deficiencies 39 were available for complete follow-up. After specific replacement therapy 23 patients were free from ulcers durins follow-up. Eleven patients showed a definite im provement and 5 were not helped (Table 5).

In the iron deficient group 7 out of 17 had कै complete remission, 7 showed a definite improve $-\overrightarrow{0}$ ment and in 3 there was no change. One patient who. had a remission with oral iron relapsed after treat $\vec{\omega}$ ment but was subsequently found to be irons deficient once again and following treatment had $£$ further complete remission. In the patients with pure folate deficiency 3 out of 6 had no ulcers after treatment, 2 were improved and one was unaffected by treatment. In the 6 patients with vitamin $B_{12}$ dẹo ficiency, 4 had a complete remission, one was im proved and one was not helped. Of the 10 remaining patients with combined deficiencies, 9 showed $\mathrm{a}^{\mathrm{P}}$ complete remission and 1 was improved.

\section{Discussion}

In the present series of 328 patients with recurrent? aphthae, 45 had deficiencies of iron, folic acid \&rvitamin $B_{12}$ singly or combined. In each case $\overrightarrow{0}$ examination of the peripheral blood was combin 6000 with estimations of serum iron, total iron binding capacity, whole blood folate and serum vitamin $\overrightarrow{B_{12}}$. The majority of patients with deficiencies hads recognizable abnormalities in the peripheral blood however, more than $33 \%$ had no demonstrable changes in the peripheral blood and screening by this means alone would have been insufficient, $\overrightarrow{\overrightarrow{0}}$ especially in patients with iron and folic acid ${ }^{3}$ deficiency.

Only in the patients with vitamin $\mathbf{B}_{12}$ deficiency? was examination of the peripheral blood alone a음 reliable screening method; this was true whether the deficiency was pure or occurred in combination with 3 iron or folic acid (Table 1). The number in this group was rather small, however, to suggest that vitamin

TABle 5. Response to replacement therapy in deficiento patients with recurrent aphthae

\begin{tabular}{|c|c|c|c|c|}
\hline Deficiency & $\begin{array}{l}\text { Complete } \\
\text { remission }\end{array}$ & Improved & Unchanged & Total \\
\hline Iron & 7 & 7 & 3 & 17 \\
\hline Folate & 3 & 2 & 1 & 6 \\
\hline Vitamin $B_{12}$ & 4 & 1 & 1 & 6 \\
\hline $\begin{array}{l}\text { Combined } \\
\text { deficiencies }\end{array}$ & 9 & 1 & - & 10 \\
\hline Total & 23 & 11 & 5 & 39 \\
\hline
\end{tabular}


$B_{12}$ assays are unnecessary in a screening programme. It is recommended that screening of patients with recurrent aphthae should include assays of whole blood folate, serum iron measurements and possibly vitamin $B_{12}$ as well as peripheral blood examination.

The incidence of minor, major and herpetiform ulcers was recorded in the deficient pateints (Table 2). There was clinical evidence of more than one type of ulcer in $27 \%$ during their attendances and there was no consistency between the type of ulcer and a particular deficiency. The sites of ulcers in the mouth were also recorded, and although ulceration of the dorsal surface of the tongue and the soft palate was more frequently seen in deficient patients than in the group as a whole, this was not sufficiently specific to be of help when screening individual patients. For those reasons, it is not felt that the clinical features of such ulcers are diagnostically helpful in determining which patients may have underlying deficiencies.

Glossitis and angular cheilitis occurred in $21 \%$ of patients with a deficiency and the presence of either of these conditions concurrently with recurrent aphthae was more suggestive of an underlying haematological deficiency. Haematological examination, however, is still necessary to characterize the deficiency itself.

In this series, 39 patients were followed-up to determine their response to replacement therapy. In total, 23 patients had a complete remission of ulcers, 11 were improved and 5 were unaffected (Table 5). Of the patients with pure iron deficiency, 7 had a complete remission, 7 were improved and 3 were unchanged. In the 6 folate-deficient patients, 3 became entirely free of ulcers and 2 were improved, while in those patients with vitamin $\mathbf{B}_{12}$ deficiency 4 out of 6 were free of ulcers during follow-up and 1 was improved. The relatively poor response with iron has previously been noted and may reflect the difficulty of replacing iron stores with oral therapy, especially in the presence of continuing blood loss as in menorrhagia. In contrast, replacement of vitamin $B_{12}$ and folic acid is easily achieved.

From the findings in this series there is a $14 \%$ chance of patients with persistent recurrent aphthae having some form of haematological deficiency. It was not possible by clinical examination of the ulcers to identify patients with an underlying deficiency or disease from those with no such abnormality. All patients presenting in this way should, therefore, undergo haematological screening.

\section{References}

BAINTON, D.F. \& Finch, C.A. (1964) The diagnosis of iron deficiency anemia. American Journal of Medicine, 37, 62.

Challacombe, S.J., Barkham, P. \& Lehner, T. (1977) Haematological features and differentiation of recurrent oral ulceration. British Journal of Oral Surgery, 15, 37.

DACIE, J.W. \& Lewis, S.M. (1970) Practical Haematology, 4th edn. Churchill Livingstone, Oxford.

LEHNER, T. (1968) Recurrent oral ulceration and Behçet's syndrome; pathological, and clinical study, M.D. thesis, University of London.

WAters, A.H. \& Mollin, D.L. (1961) Studies on the folic acid activity of human serum. Journal of Clinical Pathology, $14,335$.

Wray, D., Ferguson, M.M., Mason, D.K., Hutcheon, A.W. \& DAGG, J.H. (1975) Recurrent aphthae; treatment with vitamin $\mathbf{B}_{12}$, folic acid, and iron. British Medical Journal, 2, 490.

Young, D.S. \& Hicks, J.M. (1965) Method for the automatic determination of serum iron. Journal of Clinical Pathology, 18, 98. 